\title{
Перспективы золотоносности Северо-востока России по оценке геохимической специализации рудовмещающих структур
}

Пилицын А.Г. ${ }^{1}$, Волков А.В. ${ }^{2}$

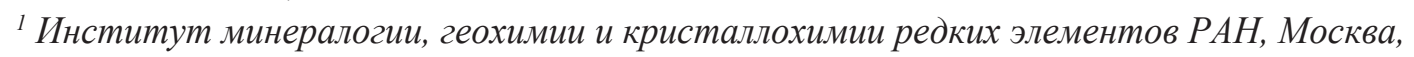
allexpil@yandex.ru

${ }^{2}$ Институт геологии рудных месторождений, петрографии, минералогии и геохимии РАН, Москва, tma2105@mail.ru

Аннотация. Проведена интерпретация сводной базы геохимических данных потоков рассеяния м-ба 1:200 000 и 1:1 000000 Северо-востока России. Основываясь на мультипликативном показателеAu*Ag*As, выделены перспективные золотоносные зоны глобального ранга в пределах внешней зоны Охотско-Чукотского вулканогенного пояса (ОЧВП). Для рудовмещающих структур золотоносных зон определена геохимическая специализация по показателю $\mathrm{Au} / \mathrm{Ag}$. Сделан вывод о преобладающей $\mathrm{Au}-\mathrm{Ag}$ специализации территории Северо-востока России и о его высокой перспективности на обнаружение новых золоторудных объектов. Даны рекомендации по постановке поисковых работ.

Ключевые слова: Северо-восток России, ОЧВП, перспективы золотоносности, региональная геохимия.

\section{Prospects for gold content in the North-East of Russia according to the assessment of the geochemical specialization of the ore-bearing structures}

Pilitsyn A.G. ${ }^{1}$, Volkov A.V. ${ }^{2}$

${ }^{1}$ Institute of Mineralogy, Geochemistry and Crystal Chemistry of Rare Elements RAS, Moscow, allexpil@yandex.ru

${ }^{2}$ Institute of Geology of Ore Deposits, Petrography, Mineralogy and Geochemistry RAS, Moscow, tma2105@mail.ru

Abstract. Interpretation of the geochemical data consolidated base of dispersion trains of scale 1: 200,000 and 1: 1000000 in the North-East of Russia has been carried out.Based on the multiplicative indicator $\mathrm{Au}^{*} \mathrm{Ag}^{*} \mathrm{As}$, promising gold-bearing zones of a global rank have been identified within the outer zone of the Okhotsk-Chukotka volcanogenic belt (OChVB).For the ore-bearing structures of the gold-bearing zones, geochemical specialization has been determined in terms of $\mathrm{Au} / \mathrm{Ag}$. The conclusion is made about the prevailing $\mathrm{Au}-\mathrm{Ag}$ specialization of the territory of the North-East of Russia and about its high prospects for the discovery of the new gold-ore objects. Recommendations for prospecting works are given.

Key words: North-East of Russia, Okhotsk-Chukotka volcanic belt, prospects of gold content, regional geochemistry.

На Северо-востоке России в Магаданской области разведано более 2000 т или $14 \%$ российских запасов золота, еще почти $5 \%$ российских запасов содержится в месторождениях Чукотского АО. Вместе с тем, большая часть территории Северо-востока, в связи с удаленностью и труднодоступностью изучена весьма слабо. Поэтому направление дальнейших среднемасштабных поисковых работ на золото - весьма актуальная задача на сегодняшний день.

Сводное и обзорное геохимическое картирование - основной инструмент локализации перспективных площадей для постановки среднемасштабных поисковых работ на различные виды полезных ископаемых. Основная задача такого картирования, это структурирование геохимического поля с выделением геохимических зон и районов, связанных с глобальными рудообразующими процессами.

Современные программные средства рассчитаны на обработку практически неограниченных массивов геохимических данных и позволяют проводить интерпретацию в сводном масштабе без использования генерализации, напрямую по моно- и полиэлементным геохимическим картам на 


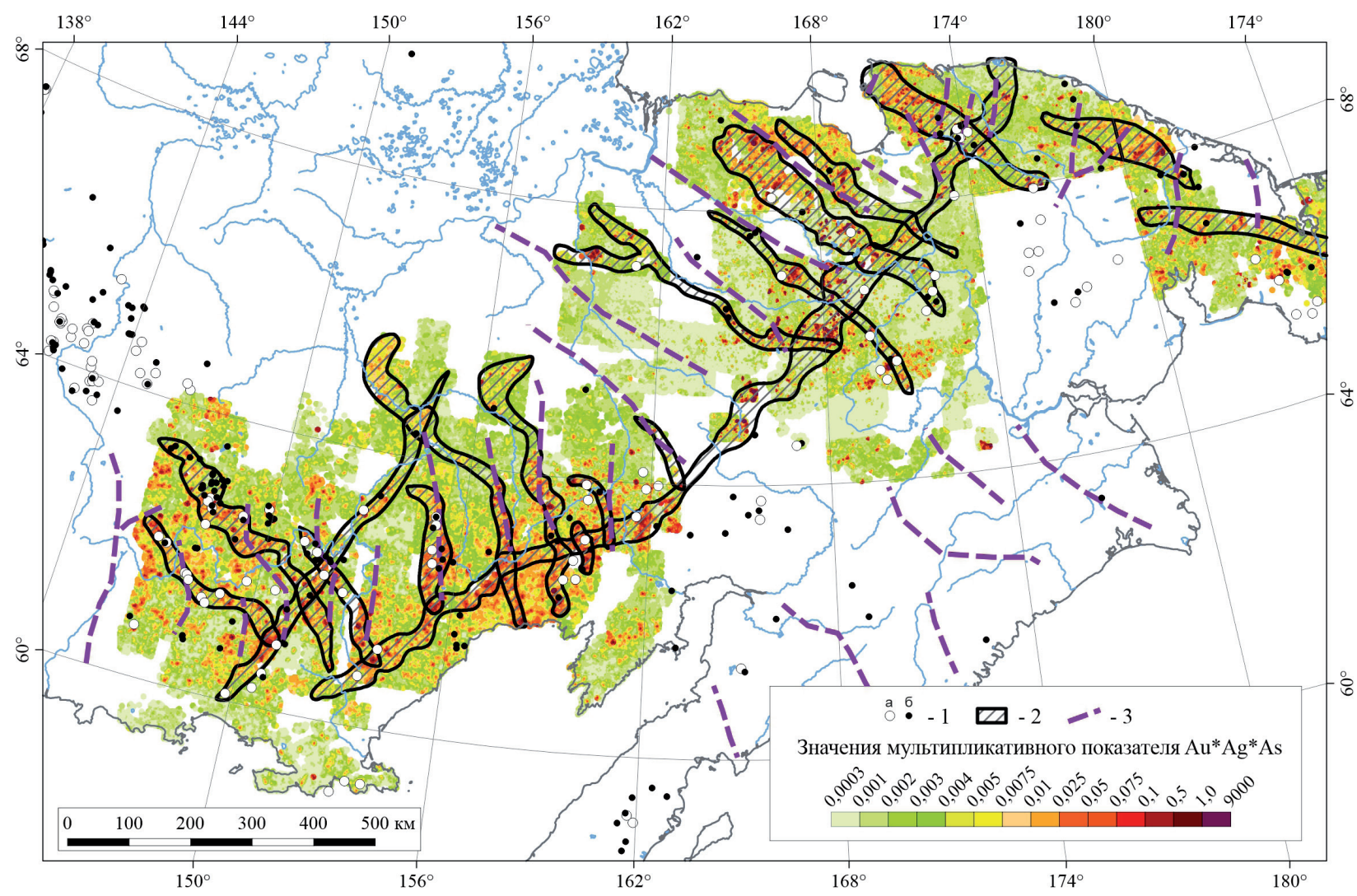

Рис. 1. Геохимические золотоносные зоны на схеме распределения мультипликативного показателя $\mathrm{Au}$ * $\mathrm{Ag}$ * $\mathrm{As}$. 1 - месторождения (а) и проявления (б) золота; 2 - перспективные геохимические золотоносные зоны; 3 - оси зон ТМА (по Волков А.В., 2005).

Fig. 1. Geochemical gold-bearing zones on the scheme of distribution of the multiplicative indicator $\mathrm{Au}^{*} \mathrm{Ag} \mathrm{As}^{*}$. 1 - Deposits (a) and manifestations (б) of gold; 2 - promising geochemical gold-bearing zones; 3 - axes of TMA zones.

большие территории, что позволяет установить пространственные закономерности геохимических полей связанными с глобальными рудообразующими процессами.

На территории Северо-востока России проведено обобщение архивных данных геохимической съемки по потокам рассеяния 1:200 000 - 1:1 000000 масштаба, которые были сведены в единую сводную базу данных (СБД). Основной объем геохимических исследований пришелся на 70-е и 80-е годы, когда полистно проводилась геохимическая съемка по потокам рассеяния м-ба 1:200 000 ( 75 \% всей территории). Всего для составления СБД использовано более 100 локальных полистных баз данных, которые суммарно включают 388355 проб.

СБД состоит из результатов анализов (преимущественно ХC $\mathrm{Au}^{1}$ и ПКСА²) на следующие компоненты: Au (100 \% анализов от общей базы), Mn (100\%), Cu (100\%), Zn (100\%), Pb (100\%), Co (99\%), Ni (99\%), Sn (99\%), Mo (98\%), Be (97\%), Cr (97\%), As (97\%), W (97\%), V (96\%), Bi (95\%), Ag (94\%), Ba (91 \%), Hg (88 \%), Ti (82\%), Ga (80\%), Sb (75\%), Li (73\%), Ge (73\%).

На рассматриваемой территории широко развиты объекты $\mathrm{Au}-\mathrm{Ag}$ адуляр-кварцевого и $\mathrm{Au}-$ малосульфидного-кварцевого рудноформационных типов. Геохимические параметры в потоках рассеяния подобных объектов, по данным факторного анализа,представлены ассоциациями: для первого типа - Au, Ag, As, Cu, Zn, Pb, Mo, Sn, Bi, Hg; для второго - Au, As, Sb, W ( $\mathrm{Hg}, \mathrm{Cu}, \mathrm{Ag}$ ).

Минимально необходимая ассоциация для выделения золоторудных объектов большинства типов - мультипликативный показатель $\mathrm{Au}^{*} \mathrm{Ag}^{*} \mathrm{As}$ (рис. 1), который имеет на территории Северо-

\footnotetext{
${ }^{1}$ Химико-спектральный анализ на $\mathrm{Au}$

2 Полуколичественный спектральный анализ.
} 
Востока довольно контрастный характер. В результате по этому показателю, выделена глобальная геохимическая зона северо-восточного простирания протяженностью 1500 км и шириной до 100 км в пределах внешней перивулканической зоны ОЧВП. Также хорошо локализованы по этому показателю зоны тектоно-магматической активизации (ТМА) (Волков, 2005). Пространственная корреляция показывает, что большинство Au-Agи Аuместорождений лежит в границах выделенных зон, в том числе крупныеместорождения Купол и Майское.

Для геохимической специализации использовано отношение Au/Ag (Волков А.В. и др., 2013 г.), которое позволяет выделить: существенно $\mathrm{Ag}$ (меньше 1/250), Au-Ag (1/250-1/25), существенно $\mathrm{Au}$ (больше 1/25). Распределение показателяAu/Agрассчитывалось только для значимых проб, где концентрации Auи $\mathrm{Ag}$ выше фоновых значений $\left(\mathrm{Au} \mathrm{C}_{\text {фон }}-0.003\right.$ г/T, $\mathrm{Ag} \mathrm{C}_{\text {фон }}-0,5$ г/T).

Получена зональная структура геохимического поля (рис. 2) распределения показателя $\mathrm{Au} / \mathrm{Ag}$. В пределах внешней зоны ОЧВП существенно сниженные значения $\mathrm{Au} / \mathrm{Ag}$ от 1/250 до 1/8 (1/3), что отвечает $\mathrm{Au}-\mathrm{Ag}$ и существенно $\mathrm{Au}$ (нижний порог) специализации. К периферии внешней зоны ОЧВП на северо-запад, а также во внутренней зоне ОЧВП, концентрация показателя $\mathrm{Au} / \mathrm{Ag}$ значительно возрастает от $1 / 8$ до $>1.2$, что отвечает существенно Аu специализации.

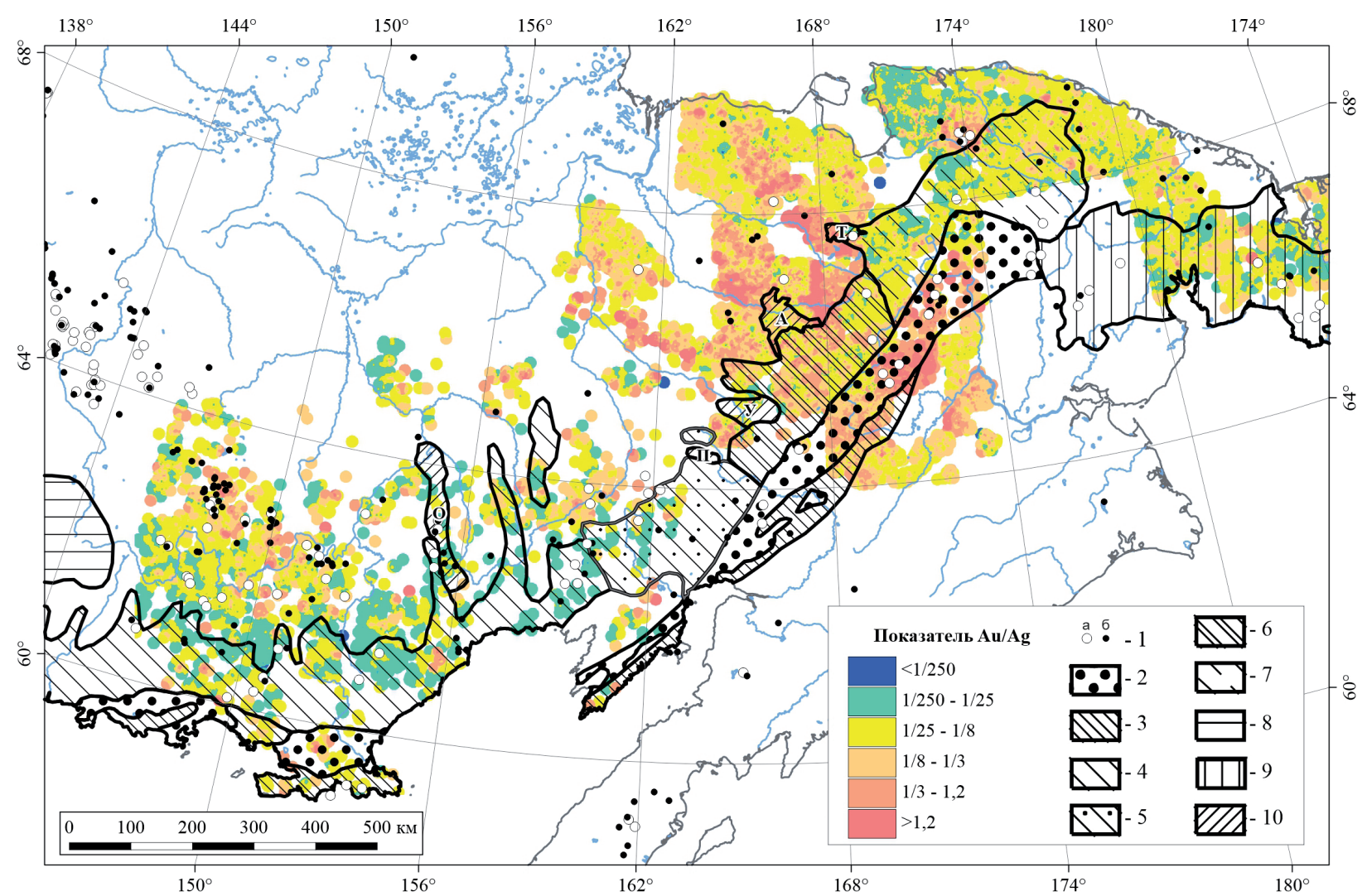

Рис. 2. Схема распределения показателя $\mathrm{Au} / \mathrm{Ag}$ на схеме районирования ОЧВП.

1 - месторождения (а) и проявления (б) золота;2 - вулканиты внутренней зоны; 3 - магматогенные поднятия; 4-7 - внешняя зона, секторы: 4 - Охотский; 5 - Пенжинский; 6 - Анадырский; 7 - Центрально-Чукотский; 8-9 - фланговые зоны: 8 - Западно-Охотская; 9 - Восточно-Чукотская; 10 - позднеорогенные структуры (конец баррема-начало альба) мезозоид: О - Омсукчанский грабен; П - Верхне-Пенжинская; У - Умкувеемская; А - Айнахкургенская; Т- Тытыльвеемская впадина.

Fig. 2. Scheme of distribution of the $\mathrm{Au} / \mathrm{Ag}$ indicator on the scheme of regionalization of Okhotsk-Chukotka volcanic belt. 1 - deposits (a) and manifestations (б) of gold; 2 - volcanics of the inner zone; 3 - magmatogenic uplifts; 4-7 - outer zone, sectors: 4 - Okhotsk; 5 - Penzhinsky; 6 - Anadyr; 7 - Central Chukotka; 8-9 - flank zones: 8 - West Okhotsk; 9 - East Chukotka; 10 - late orogenic structures (end of the Barremian - beginning of the Albian) of the Mesozoic: $\mathrm{O}$ - Omsukchan graben; P - Verkhne-Penzhinskaya; U - Umkuveemskaya; A - Ainakhkurgen; T - Tytylveemskaya depression. 


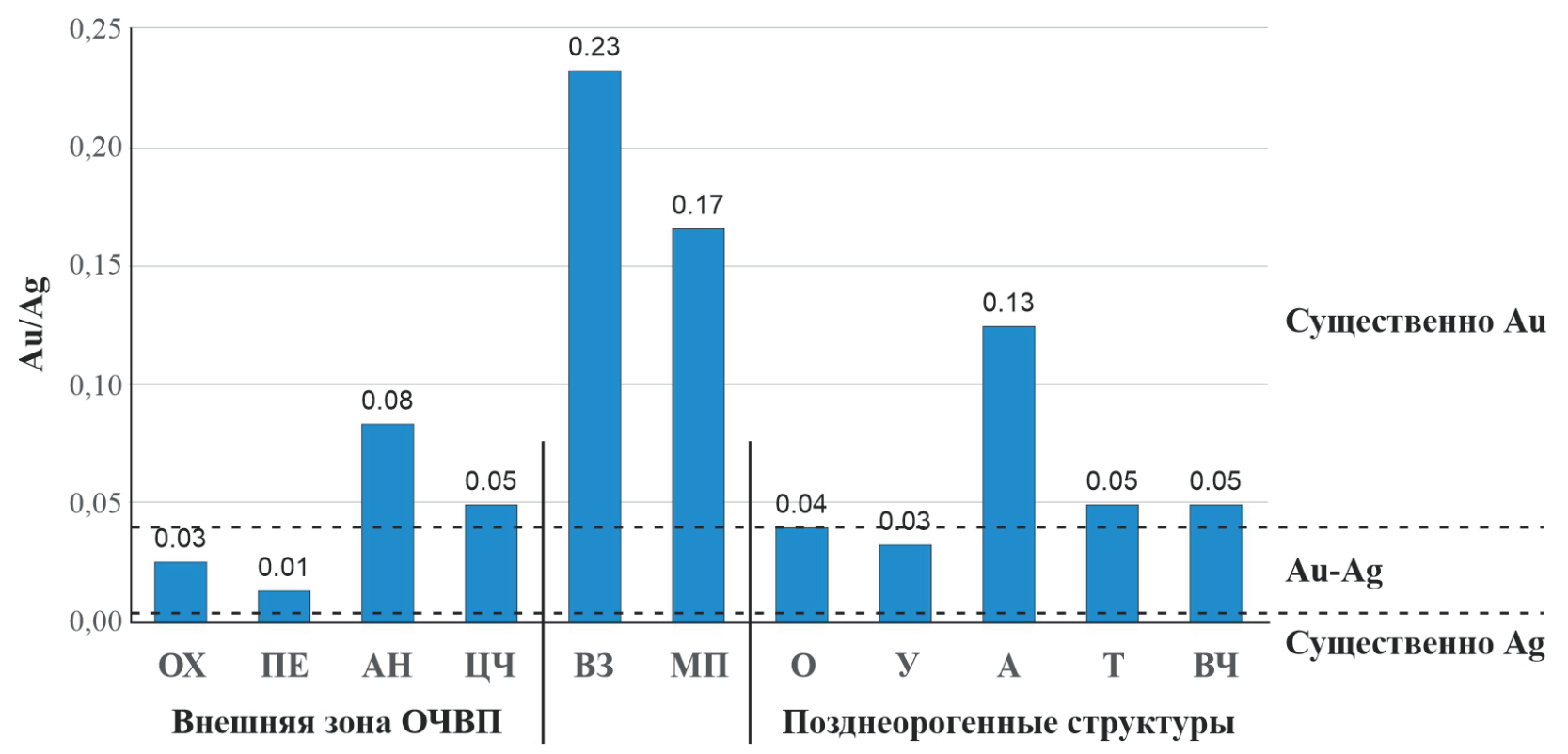

Рис. 3. Средние значения коэффициента $\mathrm{Au} / \mathrm{Ag}$, для структур ОЧВП.

Внешняя зона ОЧВП: ОХ - Охотский; ПЕ - Пенжинский; АН - Анадырский; ЦЧ - Центрально-Чукотский; В3 - вулканиты внутренней зоны; МП - магматогенные поднятия; позднеорогенные структуры мезозоид: О - Омсукчанский грабен; П - Верхне-Пенжинская; У - Умкувеемская; А - Айнахкургенская; Т - Тытыльвеемская впадина.

Fig. 3. Average values of the Au / Ag coefficient for OCVB structures.

Outer zone of the Okhotsk-Chukotka volcanic belt: OX - Okhotsk; ПЕ - Penzhinsky; АН - Anadyr; ЦЧ - Central Chukotka; B3 - volcanic rocks of the inner zone; MП - magmatogenic uplifts; Late orogenic structures of the mesozoids: O - Omsukchan graben; П - Verkhne-Penzhinskaya; У - Umkuveemskaya; A - Ainakhkurgen; T - Tytylveemskaya depression.

В пределах каждой структуры был рассчитан средний показатель отношения $\mathrm{Au} / \mathrm{Ag}$ (pис. 3). Внешняя зона ОЧВП относится к $\mathrm{Au}-\mathrm{Ag}$ типу от 0.01 до 0.08 (среднее - 0.04). Внутренняя зона имеет более высокий показатель $\mathrm{Au} / \mathrm{Ag}-0.23$ и относится к $\mathrm{Au}$ типу. Для большинства остальных исследованных структур показатель $\mathrm{Au} / \mathrm{Ag}$ не высокий от 0.013 до 0.05 (исключение Айнахкургенская структура - 0.13), что говорит о преобладающей $\mathrm{Au}-\mathrm{Ag}$ специализации эпитермальных месторождений Северо-востока Россиии о его высокой перспективности на обнаружение новых золоторудных объектов.

Перспективные направления среднемасштабных геохимических работ связанны с неизученными территориями в контурах выделенных золоторудных зон, в пределах которых выделены 16 перспективных площадей для постановки поисковых работ. Отметим, что на границе Чукотского $\mathrm{AO}$ и Магаданской области остались не изученными листы Q-58-XXXI-XXXIV,a на продолжении Баимской зоны -листы Q-58-VII, VIII. Эти площади - первоочередные для проведения среднемасштабных геохимических работ.

\section{Литература}

1. Волков А.В., Чижова И.А., Алексеев В.Ю, Сидоров А.А. Вариации показателя $\mathrm{Ag} / \mathrm{Au}$ эпитермальных месторождений // Доклады Академии наук. 2013. Т. 452. № 1. С. 75-79.

2. Волков А.В. Закономерности размещения и условия формирования золоторудных месторождений в зонах тектоно-магматической активизации Северо-Востока России // Геология рудных месторождений. Москва. 2005. 19 с. УДК: 553.411.2:553.261. 